\title{
NÍVEL COGNITIVO REQUERIDO NOS EXAMES DE SUFICIÊNCIA DO CFC NA PERSPECTIVA DA TAXONOMIA DE BLOOM
}

\section{COGNITIVE LEVEL REQUIRED ON CFC's SUFFICIENCY EXAMINATIONS IN THE PERSPECTIVE OF BLOOM'S TAXONOMY}

“O artigo foi aprovado e apresentado no XII Congresso Anpcont, realizado de 9 a 12/6 de 2018, em João Pessoa (PB)".

\section{RESUMO}

Este estudo teve como objetivo avaliar o nível cognitivo das questões de Contabilidade do Exame de Suficiência do Conselho Federal de Contabilidade (CFC), no período de 2014 a 2016, de acordo com a Taxonomia de Bloom. Para isso, foi realizada a análise do conteúdo das provas do Exame de Suficiência, desde a primeira edição de 2014 até a segunda edição de 2016, e consideradas as questões especificamente relacionadas à Contabilidade. Adicionalmente, foi feita uma comparação entre o nível cognitivo das questões e os resultados obtidos nos exames aplicados no período (aprovações e reprovações). A principal contribuição do estudo é permitir analisar se a redução do número de aprovados no Exame de Suficiência pode estar relacionada com um aumento do nível de complexidade das questões, com base na Taxonomia de Bloom. Os resultados mostraram que o número de questões classificadas no menor nível cognitivo de todas as edições analisadas foi inferior ao número de questões classificadas no maior nível cognitivo, exceto na primeira edição de 2015, o que pode ser um indício para os altos índices de reprovação no exame. Em outras palavras, existe a possibilidade de os índices de reprovação estarem crescendo devido ao aumento da exigência de maior nível cognitivo nas questões. Nesse sentido, pode ser que os cursos de graduação em Ciências Contábeis não estejam privilegiando os objetivos educacionais, notadamente, aqueles que proporcionam atingir níveis cognitivos mais elevados.

Palavras-chave: Exame de Suficiência em Contabilidade; Nível Cognitivo; Taxonomia de Bloom.

\begin{abstract}
The aim of this study was to evaluate the cognitive level of the questions of Accounting of the Sufficiency Exam of the Federal Accounting Council, from 2014 to 2016, according to the Bloom's Taxonomy. For this purpose, the content of the tests of the Sufficiency Exam was analyzed, from the first edition of 2014 until the second edition of 2016, and considering the questions specifically related to Accounting. In addition, a comparison was made between the cognitive level of the questions and the results obtained in the examinations applied in that period (approvals and disapprovals). The main contribution of this study is to allow the analysis of whether the reduction in the number of approved subjects in the Sufficiency Exam can be related to an increase in the level of complexity of the questions, based on the Bloom's Taxonomy. The results showed that the number of questions classified in the lowest cognitive level of all analyzed editions was lower than the number of questions classified at the highest cognitive level, except in the first edition of 2015, which may be an indication for the high failure rates in the exam. In other words, there is a possibility that failure rates are increasing due to the increased demand for higher cognitive questions. In this sense, it may be that undergraduate courses in Accounting Sciences are not privileging educational objectives, especially those that provide higher cognitive levels.
\end{abstract}

Keywords: Sufficiency Exam in Accounting; Cognitive Level; Bloom's Taxonomy.

\begin{abstract}
Isabela Gomes Bernardes
Graduada em Ciências Contábeis pela Faculdade de Ciências Contábeis da Universidade Federal de Uberlândia (Facic/ UFU). Contato: Av. João Naves de Ávila, 2121, campus Santa Mônica, Uberlândia, MG, CEP: 38.400-902. E-mail: isabela_ gomes95@hotmail.com
\end{abstract}

\section{Denise Mendes da Silva}

Doutora em Controladoria e Contabilidade pela Faculdade de Economia Administração e Contabilidade de Ribeirão Preto, Universidade de São Paulo (FEA-RP/USP). Docente da Faculdade de Ciências Contábeis da Universidade Federal de Uberlândia (Facic/UFU). Contato: Av. João Naves de Ávila, 2121 campus Santa Mônica, Uberlândia, MG, CEP: 38.400-902. E-mail: denise mendes@ufu.br 


\section{INTRODUÇÃO}

As áreas de atuação do contador estão em constante mudança, exigindo profissionais preparados para atuar em um cenário econômico, político e social cada vez mais oscilante. Torna-se essencial, então, atualizar os conteúdos de formação dos graduandos em Contabilidade para que haja uma harmonia entre os currículos e as demandas contemporâneas.

As demonstrações financeiras das empresas brasileiras, por exemplo, devem ser elaboradas em conformidade com as International Financial Reporting Standards (IFRS), normas internacionais de Contabilidade. Essas normas trazem princípios que exigem dos gestores, contadores e auditores a capacidade de julgar e tomar decisões, ou seja, faz-se necessário que as Instituições de Ensino Superior (IES) desenvolvam um ensino que capacite os alunos de Contabilidade a fazer julgamentos e tomar decisões de acordo com os princípios contábeis, levando em consideração os aspectos evolutivos das práticas contábeis.

Uma das formas de avaliar os conhecimentos dos bacharéis em Ciências Contábeis, adquiridos ao longo do curso de graduação, é o Exame de Suficiência, aplicado duas vezes ao ano pelo Conselho Federal de Contabilidade (CFC). Embora a percepção dos contadores em relação ao Exame de Suficiência seja positiva, acreditando que essa forma de avaliação reflete uma valorização profissional e seleciona os profissionais mais capacitados, conforme apontou Galvão (2016), o que se tem observado é um baixo desempenho dos bacharéis nesse exame.

Bugarim et al. (2014a) realizaram uma análise histórica dos resultados do Exame de Suficiência do CFC de 2000 a 2004 e de 2011 a 2012 e verificaram um decréscimo significativo nos níveis de aprovação, que passaram de 83,5\% na primeira edição em 2000 para 23,8\% em 2012. Nos últimos anos (2014-2016), foi possível observar, também, uma redução do número de aprovados, conforme as estatísticas divulgadas pelo CFC em seu site (vide: http://cfc.org.br/ registro/exame-de-suficiencia/relatorios-estatisticos-do-exame-de-suficiencia/). Na segunda edição de 2015, por exemplo, houve um pico de reprovações (85\%).

Explicações para esses resultados podem estar relacionadas à qualidade dos cursos de graduação e ao desempenho dos discentes (BUGARIM et al., 2014a; SOUZA; CRUZ; LYRIO, 2017). Gonzales e Ricardino Filho (2017) alertam para problemas de transparência na divulgação dos resultados do Exame de Suficiência pelo CFC, o que pode dificultar uma análise mais objetiva dos motivos relacionados ao desempenho nas provas. A divulgação do número de inscritos aprovados e reprovados por instituição de ensino contábil, por exemplo, poderia ajudar na investigação de aspectos da qualidade dos cursos.

Bugarim et al. (2014a, p. 134) destacam que, "considerando que não houve mudança no nível de dificuldade das provas ao longo das edições do exame do CFC, o aumento significativo e generalizado dos níveis de reprovação podem apenas ser imputados à uma formação profissional que, ao invés de evoluir, acabou por regredir em termos qualitativos". Contudo, a literatura acerca do nível de dificuldade das provas é incipiente.

Pinheiro et al. (2013) fizeram uma análise das questões da segunda edição do Exame de Suficiência de 2004 e da primeira edição do ano de 2011, além de duas edições do Exame Nacional de Desempenho dos Estudantes (Enade), baseada na Taxonomia de Bloom. A Taxonomia de Bloom, no domínio cognitivo, foca o planejamento educacional, no sentido de atingir os objetivos educacionais, de modo que o aluno parta das atividades menos complexas para as mais complexas. Os autores concluíram que a maioria das questões do Exame de Suficiência nos anos analisados possui um menor grau de dificuldade cognitiva, ou seja, focam questões menos complexas. No entanto, as pesquisas nessa perspectiva não continuaram para avaliar as edições seguintes do exame.

Santana Junior, Pereira e Lopes (2008) já haviam avaliado o nível cognitivo em questões de concursos públicos na área contábil, com resultados semelhantes àqueles encontrados por Pinheiro et al. (2013), ou seja, não foram exigidos dos candidatos ao cargo de contador (ou com especialidade em Contabilidade) os mais altos indicadores de habilidades cognitivas.

Considerando o panorama de diminuição nas aprovações no Exame de Suficiência, no qual as questões são, essencialmente, relacionadas à Contabilidade, e da baixa exigência cognitiva nessas questões no início das aplicações do exame, indicada por Pinheiro et al. (2013), a presente pesquisa busca avaliar se houve mudanças no nível cognitivo desse exame, conforme a Taxonomia de Bloom, nas edições do período de 2014 a 2016, que possam ser indícios para o aumento do número de reprovados nos últimos anos. Nesse sentido, a questão que direciona esta pesquisa é: qual o nível cognitivo das questões de Contabilidade do Exame de Suficiência do CFC no período de 2014 a 2016, na perspectiva da Taxonomia de Bloom?

O objetivo desta pesquisa é avaliar o nível cognitivo das questões de Contabilidade do Exame de Suficiência do CFC, no período de 2014 a 2016, na perspectiva da Taxonomia de Bloom. Para isso, foi realizada a análise do conteúdo das provas do Exame de Suficiência desde a primeira edição de 2014 até a segunda edição de 2016, assim como foram consideradas as questões especificamente relacionadas à Contabilidade. Adicionalmente, foi feita uma comparação entre o nível cognitivo das questões e os resultados obtidos nos exames aplicados no período (aprovações e reprovações).

A principal contribuição do estudo é permitir analisar se a redução do número de aprovados no Exame de Suficiência pode estar relacionada com um aumento do nível de complexidade das questões, baseado na Taxonomia de Bloom.

Espera-se que este estudo possa motivar as IES a acompanharem as mudanças e priorizar o desenvolvimento da capacidade cognitiva dos futuros profissionais contábeis, bem como estabelecer objetivos educacionais precisos e concisos, de modo que seja possível acompanhar sua evolução. Espera-se, também, agregar informações que sejam úteis aos órgãos responsáveis por elaborar as provas do Exame de Suficiência. 


\section{REVISÃO DA LITERATURA}

\subsection{Ensino e Avaliação em Contabilidade}

De acordo com Pinheiro et al. (2013), a formação profissional contábil deve possibilitar que os contadores sejam participantes no processo de construção de uma sociedade mais coerente. Para isso, faz-se necessário uma postura analítica, crítica e inovadora, além das competências e habilidades técnicas que lhes devem ser inerentes

Silva (2015) argumenta que é evidente que o perfil de formação exposto nas Diretrizes Curriculares Nacionais propõe a formação de um profissional com conhecimentos contábeis, financeiros e gerenciais úteis no contexto econômico globalizado e impactado pelas tecnologias de informação e comunicação. Conforme Slomski et al. (2010), os currículos devem atender às necessidades dos alunos de acordo com as exigências contemporâneas. As IES devem estar atentas aos conteúdos que estão sendo ensinados, como são transmitidos e se são efetivos para a vida cultural e prática.

Os profissionais de Contabilidade, além de ter conhecimento, compreensão e sabedoria de aplicar o que foi aprendido, devem, também, analisar, sintetizar e avaliar o conhecimento em um ambiente econômico e social cada vez mais complexo e demandante de informações. Portanto, é importante que os profissionais da Contabilidade não se limitem apenas à prática contábil, relacionada com as rotinas operacionais, mas estejam atentos às demandas sociais e de mercado (PINHEIRO et al., 2013). O contador precisa estar apto para participar de forma ativa da gestão da empresa, de modo a comunicar suas ideias e também interagir com as várias áreas da organização, não apenas identificando problemas, mas contribuindo com a solução (OTT; PIRES, 2010).

No intuito de acompanhar a aquisição desses conhecimentos, habilidades e competências, existem os sistemas de avaliação. Para Pelissoni (2010), a avaliação deve ser um processo contínuo e funcional, que permita diagnosticar a situação da aprendizagem dos alunos e a intervenção do professor na regulagem do conteúdo que é transmitido, ou seja, trata-se de uma leitura da aprendizagem. Nesse sentido, como forma de avaliar as possíveis falhas na formação profissional, surgiram mecanismos de controle e regulação da educação contábil brasileira, nos quais os graduandos e os graduados em Ciências Contábeis são submetidos à realização de duas avaliações em momentos distintos.

As duas principais formas de avaliação de estudantes e bacharéis em Ciências Contábeis no Brasil se dão por meio do Exame Nacional de Desempenho dos Estudantes (Enade), aplicado pelo Instituto Nacional de Estudos e Pesquisas Educacionais Anísio Teixeira do Ministério da Educação e Cultura (Inep/MEC), e por meio do Exame de Suficiência, aplicado pelo Conselho Federal de Contabilidade (CFC), como requisito para a obtenção de registro para a atuação profissional, estabelecido pelo art. 12 do Decreto-Lei n. ${ }^{\circ}$ 9.295/46, com redação dada pela Lei n. ${ }^{\circ}$ 12.249/2010.

O Exame de Suficiência foi instituído no Brasil em 1999 como um dos requisitos para a obtenção de registro profissional em Conselho Regional de Contabilidade (CRC), conforme o art. $1^{\circ}$ da Resolução CFC n. ${ }^{\circ} 853 / 99$. O estudo realizado por Bugarim et al. (2014b) apontou que o primeiro Exame de Suficiência ocorreu no segundo semestre de 2000, em todo território nacional e, devido a posturas contrárias à sua realização, por não possuir respaldo legal, o mesmo deixou de ser obrigatório em 2005. Somente em 2010, por meio da Lei n. ${ }^{\circ} 12.249 / 2010$ e da Resolução CFC n. ${ }^{\circ} 1.301 / 2010$, a obrigatoriedade do Exame de Suficiência foi novamente instituída e amparada por lei específica.

Na Resolução CFC n. ${ }^{\circ} 1.486 / 2015$, o Exame de Suficiência é definido como sendo a prova utilizada para comprovar os conhecimentos médios obtidos pelos bacharéis e estudantes do último ano letivo de Ciências Contábeis, de acordo com os conteúdos programáticos desenvolvidos no curso de Bacharelado em Ciências Contábeis, que tem como objetivo o registro na categoria de contador. Conforme o disposto no $\S 2^{\circ}$ do art. 12 do Decreto-Lei n. ${ }^{\circ} 9.295 / 46$, com redação dada pela Lei n. ${ }^{\circ} 12.249 / 2010$, desde o dia $1^{\circ}$ de junho de 2015, o exame não é mais aplicado aos técnicos em Contabilidade, isso porque os profissionais a que se refere esse Decreto-Lei somente poderão exercer a profissão após a regular conclusão do curso de Bacharelado em Ciências Contábeis, reconhecido pelo Ministério da Educação.

O exame é aplicado em todo território nacional duas vezes ao ano, de acordo com o edital publicado em cada região, sessenta dias antes da realização. O requisito para ser aprovado é obter, no mínimo, cinquenta por cento de acertos.

No artigo $6^{\circ}$ da Resolução CFC n. ${ }^{\circ}$ 1.486/2015, o Exame de Suficiência obedece às seguintes condições e áreas de conhecimento: Contabilidade Geral; Contabilidade de Custos; Contabilidade Aplicada ao Setor Público; Contabilidade Gerencial; Controladoria; Teoria da Contabilidade; Legislação e Ética Profissional; Princípios de Contabilidade e Normas Brasileiras de Contabilidade; Auditoria Contábil; Perícia Contábil; Noções de Direito; Matemática Financeira e Estatística; e Língua Portuguesa.

Percebe-se, então, que o Exame de Suficiência não só avalia o que o profissional adquiriu ao longo de sua formação, como também auxilia na qualidade técnica dos serviços contábeis, permite melhorias no ensino e, ainda, a renovação nos conteúdos trabalhados pelas universidades (KOUNROUZAN et al., 2010).

O planejamento do ensino, que culmina nos processos de avaliação, envolve o alcance de determinados objetivos educacionais. Esses objetivos podem ser categorizados conforme a taxonomia desenvolvida por Bloom em 1956. 


\subsection{Objetivos Educacionais e a Taxonomia de Bloom}

Bloom et al. (1983) definem os objetivos educacionais como sendo as modificações que o ensino produz nos pensamentos, sentimentos e ações dos alunos, por meio de formulações explícitas. Muitas são essas modificações, porém poucas permanecem, devido às limitações do tempo e à restrição de recursos. Os autores completam que formalizar os objetivos educacionais implica examinar as informações disponíveis sobre os alunos, as exigências da vida contemporânea e a natureza da matéria de ensino.

De acordo com Ferraz e Belhot (2010), é fundamental que os professores estabeleçam objetivos educacionais, considerando o conhecimento e as competências que serão adquiridas, de acordo com o perfil profissional que será formado. Isso consiste em escolher adequadamente as estratégias e os métodos que serão utilizados, delimitando o conteúdo específico e os instrumentos de avaliação que, consequentemente, resultarão em uma aprendizagem efetiva e duradoura. Pode parecer que não, mas é comum a existência de docentes que não estabelecem objetivos educacionais, improvisam, acreditam que já sabem o conteúdo da disciplina de cor ou, ainda, não preparam as aulas adequadamente, devido à ausência de tempo (PELISSONI, 2010). Quando se tem em vista os objetivos de aprendizagem que serão utilizados, o docente pode escolher a modalidade didática mais adequada para incentivar os alunos a adotarem uma abordagem de estudo mais profunda, de forma que ele se torne ativo na construção do próprio conhecimento (COSTA; PFEUTI; CASA NOVA, 2014).

Para aqueles professores que não possuem o hábito de definir o conteúdo que será aplicado na disciplina periodicamente, fazer uso de um instrumento que auxilie nessa definição seria fundamental. Nesse caso, a taxonomia proposta por Bloom no ano de 1956 poderia auxiliar o processo, visto que seu intuito é ajudar no planejamento, organização e controle dos objetivos de aprendizagem (FERRAZ; BELHOT, 2010). Portanto, entende-se que a taxonomia de Bloom possibilita tanto a definição dos objetivos educacionais como o acompanhamento do alcance dos mesmos, por meio das avaliações.

Jenoveva-Neto et al. (2013) observaram que a Taxonomia de Bloom é uma ferramenta muito interessante para analisar as habilidades que estão sendo desenvolvidas pelos alunos ao longo do processo de ensino-aprendizagem, o que favorece o controle da eficiência dos planejamentos executados. É possível aprender ou ensinar um conteúdo com objetivos diferentes, quando os diversos níveis da taxonomia são envolvidos. Isso permite que os alunos desenvolvam diferentes níveis de competências no processo de ensino-aprendizagem, que atendam a várias situações (PELISSONI, 2010).

Originalmente, a taxonomia proposta por Bloom et al. (1983) possui três domínios: cognitivo, afetivo e psicomotor. $\mathrm{O}$ domínio cognitivo inclui os objetivos relacionados à memória e ao desenvolvimento das capacidades intelectuais. $\mathrm{O}$ afetivo trata das mudanças de interesse, atitudes, valores e o desenvolvimento de apreciações. Por último, o psicomotor se refere à área das habilidades motoras.

O domínio cognitivo destaca-se por ser mais conhecido e utilizado, pois auxilia no planejamento educacional, nos objetivos, nas estratégias e nos sistemas de avaliação utilizados pelo educador. Sua estrutura é composta por seis níveis de complexidade crescente, do mais simples ao mais complexo, sendo classificados por Bloom et al. (1983) na seguinte hierarquia: conhecimento, compreensão, aplicação, análise, síntese e avaliação. O discente só consegue atingir o próximo nível após alcançar o nível anterior, conforme ilustrado na Figura 1.

Figura 1 - Níveis do domínio cognitivo - Taxonomia de Bloom

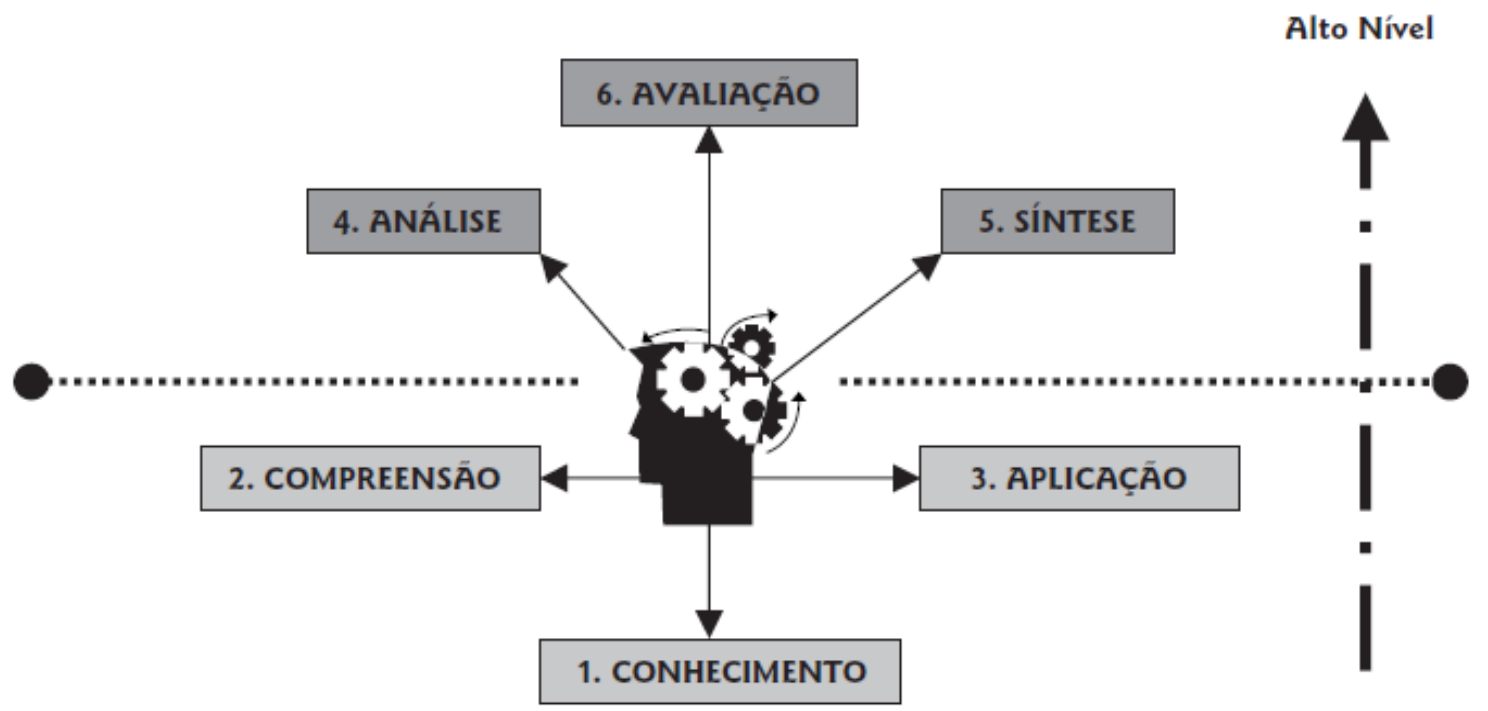

Fonte: Santana Junior, Pereira e Lopes (2008). 
Para melhor compreensão da hierarquia de complexidade dos níveis cognitivos proposta pela Taxonomia de Bloom, ilustrada na Figura 1, apresenta-se o Quadro 1, com a definição de cada um desses níveis, em linha com o apresentado por Ferraz e Belhot (2010).

\section{Quadro 1 - Definição dos níveis cognitivos - Taxonomia de Bloom}

\begin{tabular}{|c|c|}
\hline NÍVEL & DEFINIÇÃO \\
\hline Conhecimento & $\begin{array}{l}\text { Habilidade de lembrar informações e conteúdos previamente abordados como fatos, datas, palavras, } \\
\text { teorias, métodos, classificações, lugares, regras, critérios, procedimentos, etc. A habilidade pode en- } \\
\text { volver lembrar uma significativa quantidade de informação ou fatos específicos. O objetivo principal } \\
\text { desta categoria/nível é trazer à consciência esses conhecimentos. }\end{array}$ \\
\hline Compreensão & $\begin{array}{l}\text { Habilidade de compreender e dar significado ao conteúdo. Essa habilidade pode ser demonstrada } \\
\text { por meio da tradução do conteúdo compreendido para uma nova forma (oral, escrita, diagramas, } \\
\text { etc.) ou contexto. Nessa categoria, encontra-se a capacidade de entender a informação ou fato, de } \\
\text { captar seu significado e de utilizá-la em contextos diferentes. }\end{array}$ \\
\hline Aplicação & $\begin{array}{l}\text { Habilidade de usar informações, métodos e conteúdos aprendidos em novas situações concretas. } \\
\text { Isso pode incluir aplicações de regras, métodos, modelos, conceitos, princípios, leis e teorias. }\end{array}$ \\
\hline Análise & $\begin{array}{l}\text { Habilidade de subdividir o conteúdo em partes menores com a finalidade de entender a estrutura } \\
\text { final. Essa habilidade pode incluir a identificação das partes, a análise de relacionamento entre } \\
\text { as partes e o reconhecimento dos princípios organizacionais envolvidos. Identificar partes e suas } \\
\text { inter-relações. Nesse ponto, é necessário não apenas ter compreendido o conteúdo, mas também a } \\
\text { estrutura do objeto de estudo. }\end{array}$ \\
\hline Sintese & $\begin{array}{l}\text { Habilidade de agregar e juntar partes com a finalidade de criar um novo todo. Essa habilidade en- } \\
\text { volve a produção de uma comunicação única (tema ou discurso), um plano de operações (propostas } \\
\text { de pesquisas) ou um conjunto de relações abstratas (esquema para classificar informações). Combi- } \\
\text { nar partes não organizadas para formar um "todo". }\end{array}$ \\
\hline Avaliação & $\begin{array}{l}\text { Habilidade de julgar o valor do material (proposta, pesquisa, projeto) para um propósito específico. } \\
\text { O julgamento é baseado em critérios bem definidos que podem ser externos (relevância) ou internos } \\
\text { (organização) e podem ser fornecidos ou conjuntamente identificados. Julgar o valor do conhecimento. }\end{array}$ \\
\hline
\end{tabular}

Fonte: Adaptado de Ferraz e Belhot (2010).

Pode-se observar, no Quadro 1, a evolução dos objetivos educacionais conforme a Taxonomia de Bloom, que parte dos objetivos mais simples, como lembrar e classificar informações (conhecimento), passando pela habilidade de compreender a informação, mesmo que em contextos diferentes (compreensão), e pela capacidade de aplicar o conhecimento em novas situações (aplicação), até chegar aos objetivos mais complexos, que envolvem a habilidade de segregar conteúdos e identificar suas inter-relações (análise) e, posteriormente, ser capaz de organizar partes de determinadas matérias de uma nova forma (síntese), atingindo o nível mais alto, que possibilita realizar julgamentos (avaliação).

De modo geral, o processo de ensino-aprendizagem deve ser planejado para buscar atender aos objetivos educacionais. Conforme Pinheiro et al (2013), educar seria impossível sem os mecanismos de planejamento, de forma a contribuir com a elaboração de ementas, programas, metodologias e avaliações capazes de garantir o sucesso no processo de ensino-aprendizagem. Nesse sentido, os objetivos educacionais precisam estar refletidos nos instrumentos de avaliação.

\subsection{Estudos Anteriores}

Como poderá ser visto nesta seção e alinhado ao anteriormente exposto, a Taxonomia de Bloom pode ser utilizada para definição de objetivos educacionais e de estratégias de ensino-aprendizagem, em disciplinas e/ou cursos, assim como para análise do nível cognitivo de questões de instrumentos de avaliação, alvo do presente estudo.

No que tange à utilização da Taxonomia de Bloom para os objetivos educacionais, foram encontrados estudos que envolveram a análise dos cursos de Administração e Ciências Contábeis (JENOVEVA-NETO et al., 2013), as estratégias de ensino-aprendizagem utilizadas pelos docentes (COSTA, PFEUTI E CASA NOVA, 2014; COSTA et al., 2018) e a análise do nível cognitivo de questões, tanto na área contábil (DAVIDSON; BALDWIN, 2005; SANTANA JUNIOR; PEREIRA; LOPES, 2008; PINHEIRO et al., 2013; LARA; PEREIRA, 2018), quanto em outras áreas do conhecimento, como engenharia (SWART, 2010), física (AZAR, 2005; KOCAKAYA; GÖNEN, 2010) e computação (OMAR et al., 2012).

Quanto à análise dos cursos, Jenoveva-Neto et al. (2013) analisaram, por meio dos seis níveis da Taxonomia de Bloom, a tendência das habilidades cognitivas requeridas dos acadêmicos dos cursos de graduação em Administração 
e Ciências Contábeis da Universidade do Extremo Sul Catarinense (Unesc). Os autores classificaram os conteúdos de formação profissional, constantes nos planos de ensino, de acordo com a taxonomia e compararam com os objetivos educacionais registrados no Projeto Político Pedagógico dos cursos. Os resultados apontaram que nos planos de ensino há uma maior ocorrência de objetivos educacionais categorizados em níveis de menor complexidade cognitiva em comparação com os propostos no Projeto Político Pedagógico. Tal circunstância pode denotar certa incoerência, uma vez que se espera que os Projetos Políticos Pedagógicos dos cursos sejam direcionadores para demais ações.

No que tange às estratégias de ensino-aprendizagem, Costa, Pfeuti e Casa Nova (2014) analisaram duas modalidades didáticas (aula expositiva com resolução de exercícios e aula prática) com apoio da Taxonomia de Bloom e concluíram que ambas as metodologias se mostraram eficazes no sentido de auxiliar o aluno a alcançar as diferentes etapas. Os resultados indicaram, também, que não há, necessariamente, uma hierarquização entre as categorias, uma vez que houve manifestação de alunos que alcançaram a categoria avaliação mesmo que nenhum aluno tenha mostrado indícios da etapa anterior (síntese). Com isso, depreende-se que, em algumas situações, nem sempre o aluno irá empregar um nível cognitivo anterior para atingir o próximo, ou ainda, não na mesma escala proposta na taxonomia.

Por sua vez, Costa et al. (2018) apresentaram os resultados do uso do caso para ensino Open Safari no curso de Ciências Contábeis de uma universidade pública brasileira, no intuito de obter evidências quanto à sua eficácia no desenvolvimento de habilidades e competências imprescindíveis à aprendizagem e ao emprego das IFRS, analisando os resultados à luz da Taxonomia de Bloom. Os autores concluíram que o caso é eficiente no alcance dos níveis mais altos do Domínio Cognitivo de aquisição e consolidação de conhecimento, conforme a Taxonomia de Bloom. As habilidades apontadas como as mais aprimoradas referem-se à capacidade de considerar mais de uma solução para problemas reais, à interpretação de cenários, à consolidação de vários conteúdos da disciplina em que o caso foi aplicado e do curso e à associação com a prática e desenvolvimento de senso crítico e de responsabilidade individual pelo próprio aprendizado. Nesse sentido, percebe-se a importância de adequar o ensino de Contabilidade à realidade da convergência contábil, ou seja, o ensino tem que ser baseado em princípios, assim como as normas contábeis internacionais, e isso exige competências que serão desenvolvidas a partir da exploração dos níveis cognitivos mais altos da taxonomia.

A respeito do nível cognitivo de questões, Swart (2010) analisou os exames finais do curso de Engenharia, enquanto Azar (2005) e Kocaya e Gönen (2010) pesquisaram questões de Física. Swart encontrou mais questões de baixa habilidade cognitiva. Azar (2005) e Kocaya e Gönen (2010) demonstraram que as questões de Física das provas de acesso à universidade medem a capacidade de aplicação, análise, síntese e avaliação, ou seja, têm maior nível cognitivo, ao passo que as perguntas aplicadas no ensino médio focaram habilidades de compreensão, conhecimento e aplicação, que estão no menor nível cognitivo. Esse fato pode implicar em falta de planejamento do estudo de um modo geral e não apenas em cursos de graduação.

Em outra abordagem, Omar et al. (2012), considerando o desafio dos educadores em identificar se as questões propostas nos exames cumprem os requisitos da Taxonomia de Bloom em diferentes níveis cognitivos, apresentaram uma análise automatizada das questões de provas da disciplina de programação de um curso da Faculdade de Tecnologia e Ciência da Informação da Malásia, baseada em técnicas de processamento de linguagem natural (NLP) para identificar palavras-chave e verbos importantes, o que pode ajudar na identificação da categoria de uma pergunta. Os autores excluíram a análise da dificuldade das questões para o teste e concluíram que as regras do sistema podem ajudar na identificação da categoria da Taxonomia de Bloom presente nas questões dos exames. Seria uma possível alternativa para elaboração de exames mais eficazes, no sentido de mensurar o que realmente se deseja, respeitados os objetivos educacionais.

Na área contábil, Davidson e Baldwin (2005) utilizaram a Taxonomia de Bloom para analisar o conteúdo dos finais de capítulos de 41 livros de Contabilidade Intermediária, publicados entre 1934 e 2004. Esses autores encontraram material relacionado às seis categorias da Taxonomia de Bloom, porém pouco focado nos dois níveis mais altos dos objetivos educacionais. Uma implicação desse achado pode ser a dificuldade de o aluno ser aprovado em exames de certificação ao término do curso, como, por exemplo, no exame do American Institute of Certified Public Accountants (AICPA), que utiliza a Taxonomia de Bloom na construção das questões, incluindo níveis cognitivos mais altos, conforme consta na descrição do seu próprio site (vide https://www.aicpa.org/becomeacpa/cpaexam.html). Em outras palavras, ao longo do curso, o aluno pode ter contato com materiais didáticos que não privilegiam o desenvolvimento de todos os níveis cognitivos, notadamente os que requerem mais habilidades.

Santana Junior, Pereira e Lopes (2008) fizeram uma análise, por meio da Taxonomia de Bloom, das questões de algumas provas de concursos do setor público que demandam profissionais contadores. A pesquisa demonstrou que 0 grau de exigência nas provas é baixo. Os autores argumentam que, se as organizações quiserem de fato evoluir e cumprir suas missões institucionais, é necessário aprender a aprender e buscar soluções através do desenvolvimento pessoal.

Por sua vez, Lara e Pereira (2018) verificaram, sob a perspectiva da Taxonomia de Bloom, o nível de habilidade cognitiva das questões de contabilidade societária exigidas nas provas de concursos públicos para bacharéis em Ciências Contábeis, entre os anos de 2010 e 2014. Esses autores encontraram que a maioria das questões (85\%) requereram dos candidatos habilidades de compreensão e aplicação (níveis 2 e 3, respectivamente) e concluíram que os cargos de contador que possuem maior remuneração, nas três esferas de governo, tendem a não exigir questões de contabilidade societária com os níveis mais altos de habilidade cognitiva. De modo geral, fazendo um comparativo desses dois últimos estudos citados, o que se vê é que não houve evolução nas exigências de habilidades cognitivas nos exames de seleção para cargos públicos no que tange às questões de contabilidade. 
Na mesma linha dos últimos autores mencionados, Pinheiro et al. (2013) avaliaram os níveis de habilidades requeridos pelo Enade e pelo Exame de Suficiência, na perspectiva da Taxonomia de Bloom, e o perfil do contador, previsto pelo Conselho Nacional de Educação (CNE). Esses pesquisadores identificaram que o Enade requer um pouco mais de cognição, mas, se comparado ao Exame de Suficiência, ambos apresentam questões relacionadas aos menores níveis cognitivos. Os autores ainda destacam que é fundamental que os referidos exames busquem explorar questões com maiores níveis cognitivos.

Em linha com Pinheiro et al. (2013), entende-se que é fundamental que o Exame de Suficiência do CFC e o Enade busquem explorar questões voltadas para a análise, o senso crítico e a criatividade dos avaliados, de forma a contribuir para uma formação focada em gestão e tomada de decisões, e não limitada ao uso de técnicas contábeis. Considerando a Taxonomia de Bloom como um parâmetro para o estabelecimento de objetivos educacionais e para a avaliação da capacidade cognitiva, o presente estudo busca ampliar os resultados referentes à análise do nível cognitivo exigido no Exame de Suficiência, notadamente pelo aumento no número de reprovados em edições recentes desse exame. Assim, será possível observar se o nível cognitivo das questões têm se mantido ao longo das edições, conforme afirmam Bugarim et al. (2014a) ou se as provas passaram a ter questões com maior nível cognitivo, o que poderia ser mais um fator explicativo do desempenho dos bacharéis no exame.

\section{ASPECTOS METODOLÓGICOS}

De acordo com o objetivo traçado, esta é uma pesquisa descritiva, de abordagem qualitativa e quantitativa, na qual se utilizou análise de conteúdo, pois foi necessário classificar e quantificar as questões do Exame de Suficiência conforme a Taxonomia de Bloom.

As provas do Exame de Suficiência de contador das duas edições dos anos de 2014 a 2016 e os dados referentes às estatísticas dos exames realizados foram coletados do site do CFC. Este período foi escolhido por abranger as seis últimas edições do exame com dados disponíveis na época de realização da coleta (julho/2017), e, também, por considerar edições após a análise realizada em estudos anteriores (vide Pinheiro et al., 2013). Nas provas, foram consideradas as questões especificamente relacionadas à Contabilidade. Portanto, não fizeram parte do estudo as questões de Noções de Direito, Matemática Financeira, Estatística e Língua Portuguesa, visto a baixa representatividade desses conteúdos nas análises propostas (em média, 42 questões, do total de 50 que compõem cada edição do exame, são de conteúdos de Contabilidade).

Com o objetivo de analisar qual o nível cognitivo do exame, fez-se uma classificação dos níveis cognitivos das questões, de acordo com a Taxonomia de Bloom, em linha com os estudos de Santana Junior, Pereira e Lopes (2008) e Pinheiro et al. (2013), conforme demonstrado no Quadro 2. Os três primeiros níveis da Taxonomia de Bloom - conhecimento, compreensão e aplicação (CCA), foram considerados como menor nível cognitivo e os três últimos - análise, síntese e avaliação (ASA), como maior nível cognitivo.

Quadro 2 - Critérios utilizados nas classificações

\begin{tabular}{|c|c|}
\hline Classificações & Questões que tratam de: \\
\hline CCA (Conhecimento, Compreensão e Aplicação) & $\begin{array}{l}\text { 1. Conceito e classificação de Princípios Contábeis de forma } \\
\text { clara e concisa. } \\
\text { 2. Conceito e classificação de elementos patrimoniais. } \\
\text { 3. Cálculo de fatos contábeis e/ou de saldos contábeis de forma } \\
\text { isolada. } \\
\text { 4. Cálculo de taxas de retorno e de índices de forma isolada. } \\
\text { 5. Identificação de lançamentos contábeis. } \\
\text { 6. Cálculo de custo e de saldo de estoque de forma isolada. } \\
\text { 7. Identificação de fatos contábeis e de seus efeitos de forma isolada. } \\
\text { 8. Legislação e Código de Ética de forma conceitual e aplicada. }\end{array}$ \\
\hline ASA (Análise, Síntese e Avaliação) & $\begin{array}{l}\text { 1. Apresentação de saldos de elementos patrimoniais a partir de uma } \\
\text { estrutura relacionada de dados que requeira análise para resposta. } \\
\text { 2. Análise de informações contábeis para a tomada de decisão. } \\
\text { 3. Cálculo de custo e saldo de estoque a partir de informações } \\
\text { contidas em Demonstrações Financeiras, de forma não isolada. } \\
\text { 4. Cálculo da Equivalência Patrimonial a partir de dados fornecidos } \\
\text { em Demonstrações Financeiras e isoladamente. } \\
\text { 5. Encerramento de exercício de forma não isolada. } \\
\text { 6. Elaboração de Demonstrações Financeiras. } \\
\text { 7. Apresentação de justificativa nas respostas apresentadas. } \\
\text { 8. Escolha entre duas ou mais situações apresentadas. }\end{array}$ \\
\hline
\end{tabular}

Fonte: Adaptado de Pinheiro et al. (2013). 
É importante salientar o grau de subjetividade na classificação das questões, o que pode ser uma limitação do estudo. Um exemplo é o fato de que, para efeitos deste estudo, questões envolvendo o cálculo da equivalência patrimonial, tanto a partir de dados isolados como a partir de dados fornecidos por meio das demonstrações contábeis, foram consideradas no nível de análise, síntese e avaliação (ASA), diferentemente dos estudos de Santana Junior, Pereira e Lopes (2008) e Pinheiro et al. (2013). Entende-se que a equivalência patrimonial é um conceito que exige julgamento para definir sua própria aplicação, pois é empregada somente a empresas em que há influência significativa nas decisões operacionais e estratégicas por parte de outras empresas. Para atender ao aspecto de influência significativa, vários critérios devem ser levados em conta e tais critérios podem ser aplicados de maneira diferente, dependendo do julgamento profissional.

Destaca-se, ainda, que não existe uma regra ou delimitação rígida entre as características que levam à determinada classificação para as questões, sendo marcante a percepção do pesquisador para vincular cada questão ao nível cognitivo definido. Ademais, salienta-se que, neste estudo, as questões foram classificadas nos níveis cognitivos atendo-se aos conteúdos discriminados no Quadro 2, o que pode ocasionar diferenças, caso sejam considerados, por exemplo, os aspectos da taxonomia original, conforme constou no Quadro 1.

$\mathrm{Na}$ análise dos resultados obtidos nos Exames de Suficiência, foram utilizados os relatórios estatísticos gerais, disponíveis no site do CFC. São eles: resultado final, notas máximas e mínimas e acertos por conteúdo. As informações adquiridas nessa fase serviram para comparar os níveis cognitivos das questões com os índices de aprovados e reprovados.

\section{APRESENTAÇÃO E ANÁLISE DOS RESULTADOS}

Para iniciar as análises propostas e responder à questão de pesquisa, primeiramente, é necessário conhecer os conteúdos cobrados nas provas. Em média, aproximadamente $84 \%$ das questões das quatro edições do Exame de Suficiência analisadas são voltadas a assuntos específicos da Contabilidade. Como demonstrado na Tabela 1, entre os conteúdos específicos, o mais cobrado é o atinente à Contabilidade Geral, que envolve questões relacionadas a conhecimentos de contabilidade introdutória, intermediária, avançada e internacional, assim como de análise de demonstrações financeiras e cálculos de índices.

Tabela 1 - Número de questões por conteúdo e por edição do exame

\begin{tabular}{|c|c|c|c|c|c|c|}
\hline \multirow{2}{*}{ Conteúdo } & \multicolumn{6}{|c|}{ Número de questões por edição } \\
\hline & 2014.1 & 2014.2 & 2015.1 & 2015.2 & 2016.1 & 2016.2 \\
\hline Auditoria Contábil & 3 & 3 & 3 & 3 & 3 & 3 \\
\hline Contabilidade Pública & 3 & 3 & 3 & 3 & 3 & 3 \\
\hline Contabilidade de Custos & 4 & 4 & 4 & 4 & 3 & 3 \\
\hline Contabilidade Geral & 15 & 15 & 15 & 17 & 21 & 22 \\
\hline Contabilidade Gerencial e Controladoria & 4 & 4 & 4 & 4 & 3 & 4 \\
\hline Legislação e Ética Profissional & 3 & 3 & 3 & 3 & 2 & 1 \\
\hline Perícia Contábil & 3 & 2 & 2 & 2 & 3 & 3 \\
\hline Princípios e Normas & 4 & 4 & 4 & 3 & 3 & 3 \\
\hline Teoria da Contabilidade & 2 & 3 & 3 & 2 & 2 & 2 \\
\hline Total por semestre & 41 & 41 & 41 & 41 & 43 & 44 \\
\hline Total por ano & \multicolumn{2}{|c|}{82} & \multicolumn{2}{|c|}{82} & \multicolumn{2}{|c|}{87} \\
\hline
\end{tabular}

Fonte: Elaboração própria, com base nas estatísticas dos exames divulgadas pelo CFC.

Observa-se, na Tabela 1, que o número de questões relacionadas especificamente à Contabilidade aumentou nas duas edições de 2016, assim como as questões de Contabilidade Geral, que cresceram a partir da segunda edição de 2015.

Na Tabela 2, é apresentado o resultado da classificação dos níveis cognitivos das questões do Exame de Suficiência, da primeira edição de 2014 à segunda edição de 2016, juntamente com o índice de aprovados e reprovados, segregados por ano e por edição. A classificação seguiu a proposta de Santana Junior, Pereira e Lopes (2008) e Pinheiro et al. (2013), em linha com o explicitado na seção 3 . 
Tabela 2 - Classificação das questões de acordo com os níveis cognitivos

\begin{tabular}{c|c|c|c|c|c|c|c}
\hline Edições & Total de questões & CCA & \% & ASA & \% & \% aprovados & \% reprovados \\
\hline 2014.1 & 41 & 19 & 46,3 & 22 & 53,7 & 49,3 & 50,7 \\
2014.2 & 41 & 20 & 48,8 & 21 & 51,2 & 41,7 & 58,3 \\
Total & $\mathbf{8 2}$ & $\mathbf{3 9}$ & $\mathbf{4 7 , 6}$ & $\mathbf{4 3}$ & $\mathbf{5 2 , 4}$ & - & - \\
2015.1 & 41 & 23 & 56,1 & 18 & 43,9 & 54,5 & 45,5 \\
2015.2 & 41 & 12 & 29,3 & 29 & 70,7 & 14,7 & 85,3 \\
Total & $\mathbf{8 2}$ & $\mathbf{3 5}$ & $\mathbf{4 2 , 7}$ & $\mathbf{4 7}$ & $\mathbf{5 7 , 3}$ & - & - \\
2016.1 & 43 & 21 & 48,8 & 22 & 51,2 & 41,9 & 58,1 \\
2016.2 & 44 & 16 & 36,4 & 28 & 63,6 & 21,8 & 78,2 \\
Total & $\mathbf{8 7}$ & $\mathbf{3 7}$ & $\mathbf{4 2 , 5}$ & $\mathbf{5 0}$ & $\mathbf{5 7 , 5}$ & - & - \\
\hline
\end{tabular}

Notas: CCA: Conhecimento, Compreensão e Aplicação; ASA: Análise, Síntese e Avaliação.

Fonte: Elaboração própria.

Conforme a análise realizada por Pinheiro et al. (2013) nas duas edições do Exame de Suficiência (2004.2 e 2011.1), foi constatado que os últimos níveis da Taxonomia de Bloom foram poucos requeridos, sendo que os autores ressaltaram a importância de explorar questões com um nível cognitivo maior na avaliação do desempenho dos graduandos e graduados em Ciências Contábeis. Neste estudo, do ano de 2014 a 2016, foi possível verificar que a soma do número de questões classificadas no menor nível cognitivo de todas as edições foi inferior ao número de questões classificadas no maior nível cognitivo, exceto na primeira edição de 2015, diferindo dos resultados encontrados por Pinheiro et al. (2013) em edições anteriores.

Observa-se, também, que, na primeira edição de 2015, que teve mais questões classificadas no menor nível cognitivo (CCA), o número de aprovados no exame superou o de reprovados. Contrariamente, nas segundas edições dos anos de 2015 e 2016, nas quais o número de questões classificadas no maior nível cognitivo (ASA) foi percentualmente mais alto em relação às demais edições analisadas, o número de reprovados no exame também foi percentualmente mais alto. A edição do exame aplicada no segundo semestre de 2015, por exemplo, foi a que apresentou maior número de questões com alto nível cognitivo e o maior índice de reprovação no período analisado.

Isso significa dizer que existe a possibilidade de os índices de reprovação estarem crescendo devido ao aumento da exigência de maior nível cognitivo nas questões. E, se isso for verdade, pode ser que os cursos de graduação em Ciências Contábeis não estejam privilegiando os objetivos educacionais, notadamente, aqueles que proporcionam atingir níveis cognitivos mais elevados. Nesse sentido, é necessário repensar o planejamento do ensino, pois, ao contrário do que concluíram Pinheiro et al. (2013), as últimas edições do Exame de Suficiência parecem ter priorizado questões nos degraus mais elevados dos objetivos educacionais, de acordo com a Taxonomia de Bloom.

As questões de Contabilidade Geral, como mencionado anteriormente, envolvem conteúdos que seguem os padrões contábeis internacionais, ou seja, as normas internacionais de Contabilidade devem estar refletidas nas práticas contábeis brasileiras, aplicáveis nesse conteúdo. Tais questões são, também, as mais cobradas em relação aos demais conteúdos, se analisados comparativamente. Nessa perspectiva, na Tabela 3, foi feita uma classificação separada dessas questões, conforme a Taxonomia de Bloom.

Tabela 3 - Resultado da classificação das questões de Contabilidade Geral

\begin{tabular}{c|c|c|c|c|c}
\hline Edições & Total de questões & CCA & \% & ASA & \% \\
\hline 2014.1 & 15 & 11 & 73,3 & 4 & 26,7 \\
2014.2 & 15 & 11 & 73,3 & 4 & 26,7 \\
Total & $\mathbf{3 0}$ & $\mathbf{2 2}$ & $\mathbf{7 3 , 3}$ & $\mathbf{8}$ & $\mathbf{2 6 , 7}$ \\
2015.1 & 15 & 11 & 73,3 & 4 & 26,7 \\
2015.2 & 17 & 6 & 35,3 & 11 & $64,7^{\star}$ \\
Total & $\mathbf{3 2}$ & $\mathbf{1 7}$ & $\mathbf{5 3 , 1}$ & $\mathbf{1 5}$ & $\mathbf{4 6 , 9}$
\end{tabular}




\begin{tabular}{c|c|c|c|c|c}
\hline Edições & Total de questões & CCA & \% & ASA & \% \\
\hline 2016.1 & 21 & 13 & 61,9 & 8 & 38,1 \\
2016.2 & 22 & 14 & 63,6 & 8 & 36,4 \\
Total & $\mathbf{4 3}$ & $\mathbf{2 7}$ & $\mathbf{6 2 , 8}$ & $\mathbf{1 6}$ & $\mathbf{3 7 , 2}$ \\
\hline
\end{tabular}

Notas: CCA: Conhecimento, Compreensão e Aplicação; ASA: Análise, Síntese e Avaliação. * edição com maior nível cognitivo para as questões de Contabilidade Geral.

Fonte: Elaboração própria.

Nessa classificação, verifica-se que, em todos os semestres, com exceção do segundo semestre de 2015, as questões de Contabilidade Geral estão focando mais o CCA, que corresponde ao nível cognitivo mais baixo. Isso implica que, embora o conteúdo de Contabilidade Geral seja o mais frequente nas provas do Exame de Suficiência em relação aos demais conteúdos especificamente de Contabilidade, tal conteúdo não tem uma exigência cognitiva alta, ou seja, as questões estão mais focadas no nível de conhecimento, compreensão e aplicação, conforme a Taxonomia de Bloom para os objetivos educacionais.

Por outro lado, essas considerações podem não ser aplicáveis à segunda edição do Exame de Suficiência do ano de 2015, na qual as questões de Contabilidade Geral focaram um maior nível de exigência cognitiva (ASA), resultando, também, no maior índice de reprovações do período analisado. Esse fato apenas reforça as conclusões anteriores, referentes à análise das questões de Contabilidade como um todo, ou seja, há indícios de que, quanto maior o nível cognitivo das questões, maior o índice de reprovação no exame.

Para entender melhor essa discussão, no Quadro 3, é demonstrada a classificação das questões relativas ao conteúdo de Contabilidade Geral referente à segunda edição do Exame de Suficiência do ano de 2015, conforme os níveis cognitivos CCA e ASA.

Quadro 3 - Classificação das questões de Contabilidade Geral - Edição 2015.2

\begin{tabular}{|c|c|c|c|}
\hline N. ${ }^{\circ}$ da questão & CCA & ASA & As questões tratam de: \\
\hline 1 & & $\mathrm{X}$ & $\begin{array}{l}\text { Encerramento de exercício de forma não isolada } \\
\text { Elaboração de Demonstrações Financeiras }\end{array}$ \\
\hline 2 & & $\mathrm{X}$ & Elaboração de Demonstrações Financeiras \\
\hline 3 & & $\mathrm{X}$ & Elaboração de Demonstrações Financeiras \\
\hline 4 & & $\mathrm{X}$ & Escolha entre duas ou mais situações apresentadas \\
\hline 5 & $\mathrm{X}$ & & Cálculo de fatos contábeis e/ou de saldos contábeis de forma isolada \\
\hline 6 & & $\mathrm{X}$ & $\begin{array}{l}\text { Apresentação de saldos de elementos patrimoniais a partir de uma } \\
\text { estrutura relacionada de dados que requeira análise para resposta }\end{array}$ \\
\hline 7 & $\mathrm{X}$ & & Cálculo de fatos contábeis e/ou de saldos contábeis de forma isolada \\
\hline 8 & & $\mathrm{X}$ & Escolha entre duas ou mais situações apresentadas \\
\hline 9 & $\mathrm{X}$ & & Cálculo de fatos contábeis e/ou de saldos contábeis de forma isolada \\
\hline 10 & & $\mathrm{X}$ & Elaboração de Demonstrações Financeiras \\
\hline 11 & $\mathrm{X}$ & & Cálculo de fatos contábeis e/ou de saldos contábeis de forma isolada \\
\hline 12 & & $\mathrm{X}$ & $\begin{array}{l}\text { Cálculo da Equivalência Patrimonial a partir de dados fornecidos em } \\
\text { Demonstrações Financeiras e isoladamente }\end{array}$ \\
\hline 13 & $\mathrm{X}$ & & Cálculo de fatos contábeis e/ou de saldos contábeis de forma isolada \\
\hline 15 & & $\mathrm{X}$ & $\begin{array}{l}\text { Apresentação de saldos de elementos patrimoniais a partir de uma } \\
\text { estrutura relacionada de dados que requeira análise para resposta }\end{array}$ \\
\hline 16 & $\mathrm{X}$ & & Conceito e classificação de elementos patrimoniais \\
\hline 18 & & $\mathrm{X}$ & $\begin{array}{l}\text { Apresentação de saldos de elementos patrimoniais a partir de uma } \\
\text { estrutura relacionada de dados que requeira análise para resposta }\end{array}$ \\
\hline 25 & & $\mathrm{X}$ & Análise de informações contábeis para a tomada de decisão \\
\hline
\end{tabular}

Notas: CCA: Conhecimento, Compreensão e Aplicação; ASA: Análise, Síntese e Avaliação.

Fonte: Elaboração própria. 
Conforme os resultados dessa pesquisa, parece que o órgão responsável pela elaboração das provas do Exame de Suficiência (CFC) está privilegiando questões que focam conteúdos de Contabilidade que exigem análise, síntese e avaliação (ASA), nível com exigência cognitiva mais alta, de acordo com a Taxonomia de Bloom e a classificação proposta neste estudo, alinhada aos estudos de Santana Junior, Pereira e Lopes (2008) e Pinheiro et al. (2013). Nesse sentido, as IES precisam reavaliar seus currículos para verificar possíveis necessidades de adequação ao que vem sendo exigido.

Na mesma linha, os docentes podem necessitar rever os objetivos educacionais traçados para cada disciplina, bem como as metodologias de ensino empregadas, de modo a buscar preparar melhor os futuros profissionais contábeis, conforme preconizam Slomski et al. (2010), Costa, Pfeuti e Casa Nova (2014) e Costa et al. (2018).

\section{CONSIDERAÇÕES FINAIS}

O objetivo desta pesquisa foi avaliar o nível cognitivo das questões de Contabilidade do Exame de Suficiência do CFC no período de 2014 a 2016, na perspectiva da Taxonomia de Bloom. Foi feita uma comparação entre os níveis de complexidade das questões e os resultados de aprovações e reprovações obtidos nos exames.

Por meio da classificação das questões do Exame de Suficiência do período de 2014 a 2016, de acordo com os conteúdos de Contabilidade abordados e utilizando-se da perspectiva da Taxonomia de Bloom, observou-se um aumento do nível cognitivo dessas questões. Na comparação, foi possível verificar que à medida que aumentou o nível cognitivo, aumentou também o número de reprovados e vice-versa. Isso leva a crer que a formação do profissional contábil pode não estar atingindo o nível de exigência cognitiva dos Exames de Suficiência das edições em foco. Duas possíveis explicações para esse fato dizem respeito à ausência de adequada definição de objetivos educacionais por parte dos docentes nos cursos ou, ainda, à falta de compromisso dos discentes com os conteúdos estudados.

Destaca-se que a formação profissional deve ser levada em consideração pelas IES no sentido de preparar melhor os futuros contadores para um cenário cada vez mais exigente, pensando em desenvolver os objetivos educacionais que contribuam com essa formação.

O estudo utilizou os dados até o ano de 2016, pois os dados referentes aos últimos exames do ano de 2017 não estavam totalmente disponíveis na época da pesquisa (maio-julho/2017). Cabe ressaltar que a classificação das questões foi feita com base na percepção das pesquisadoras e isso é uma limitação do estudo. Há que se destacar, também, que o desempenho dos estudantes pode ser influenciado por diversas variáveis não abordadas neste estudo.

Outra limitação refere-se ao fato de classificar as questões a partir dos conteúdos tratados em cada nível cognitivo, conforme proposto por Santana Junior, Pereira e Lopes (2008) e Pinheiro et al. (2013) e não com base na Taxonomia de Bloom em sua versão original. Isso implica dizer que, dependendo da abordagem utilizada, o nível cognitivo de uma mesma questão pode ser diferente: é no que se pretende aprofundar em estudos futuros. Além disso, outras perspectivas podem ser consideradas, como, por exemplo, no que tange as matrizes curriculares para o curso de Ciências Contábeis e seu alinhamento ao que o CFC exige em seus exames.

Demais pesquisas futuras podem, ainda, analisar o nível cognitivo dos discentes de Ciências Contábeis, de acordo com a Taxonomia de Bloom, por meio da aplicação de questionários, tendo em vista que a capacidade cognitiva é requerida tanto em situações de avaliação da aprendizagem, quanto na atuação profissional.

\section{REFERÊNCIAS}

AZAR, A. Analysis of Turkish high-school physics-examination questions and university entrance exams questions according to Blooms' Taxonomy. Journal of Turkish Science Education, v. 2, n. 2, p. 144-150, 2005.

BLOOM, B. S.; ENGELHART, M. D.; FURST, E. J.; HILL, W. H.; KRATHWOHL, D. R. Taxonomia de objetivos educacionais: domínio cognitivo. 8. ed. Porto Alegre: Globo, 1983.

BUGARIM, M. C. C.; RODRIGUES, L. L.; PINHO, J. C. C.; MACHADO, D. Q. Análise histórica do Exame de Suficiência do Conselho Federal de Contabilidade. Revista de Contabilidade e Controladoria, v. 6, n. 1, p. 121-136, 2014a.

BUGARIM, M. C. C.; RODRIGUES, L. L.; PINHO, J. C. C.; MACHADO, D. Q. O desempenho dos profissionais de Contabilidade no Exame de Suficiência do CFC: uma análise de conglomerados regionais. Revista de Contabilidade e Organizações, v. 8, n. 22, p. 60-71, 2014b.

COSTA, S. A.; PFEUTI, M. L. M.; CASA NOVA, S. P. C. As estratégias de ensino-aprendizagem utilizadas pelos docentes e sua relação com o envolvimento dos alunos. Revista Evidenciação Contábil e Finanças, v. 2, n. 1, p. 59-74, 2014.

COSTA, P. S.; GOMES, G. S.; BRAUNBECK, G. O.; SANTANA, M. E. G. Um safári no Brasil: evidências sobre o ensino baseado na Estrutura Conceitual. Revista Contabilidade e Finanças, v. 29, n. 76, p. 129-147, 2018.

DAVIDSON, R. A.; BALDWIN, B. A. Cognitive skills objectives in intermediate accounting textbooks: evidence from end-of-chapter material. Journal of Accounting Education, v. 23, n. 2, p. 79-95, 2005.

FERRAZ, A. P. C. M.; BELHOT, R. V. Taxonomia de Bloom: revisão teórica e apresentação das adequações do instrumento para definição de objetivos instrucionais. Gestão \& Produção, v. 17, n. 2, p. 421-431, 2010.

GALVÃO, N. Percepção dos contadores sobre o Exame de Suficiência do CFC. Revista Catarinense da Ciência Contábil, v. 15, n. 45, p. 49-62, 2016. 
GONZALES, A.; RICARDINO FILHO, A. A. Transparência na divulgação de resultados do Exame de Suficiência do CFC. Revista Contabilidade Vista e Revista, v. 28, n. 10, p. 45-66, 2017.

JENOVEVA-NETO, R.; WATANABE, M.; MUELLER, R. R.; SANTOS, N. Análise dos cursos de Administração e Ciências Contábeis da Unesc à luz das habilidades cognitivas fundamentadas na Taxonomia de Bloom. Revista de Administração, Contabilidade e Economia, Ed. Especial Anpad, p. 309-330, 2013.

KOCAKAYA, S.; GÖNEN, S. Analysis of Turkish high-school physics-examination questions according to Bloom's Taxonomy. Asia-Pacific Forum on Science Learning and Teaching, v. 11, n. 1, p. 1-14, 2010.

KOUNROUZAN, M. C.; MILOCA, L. M.; FERRAZ, L. M. S.; PONCIANO, S. A. B. A. Importância do retorno do Exame de Suficiência. In: ENCONTRO DE ESTUDANTES DE CIÊNCIAS CONTÁBEIS, 2., 2010, Cascavel. Anais... Cascavel/PR, 2010.

LARA, L. D.; PEREIRA, E. M. Concurso público para bacharéis em Ciências Contábeis no Brasil: uma análise das provas à luz da Taxonomia de Bloom. Revista de Contabilidade da UFBA, v. 12, n. 1, p. 91-114, 2018.

OMAR N.; HARIS, S. S.; HASSAN, R.; ARSHAD, H.; RAHMAT, M.; ZAINAL, N. F. A.; ZULKIFLI, R. Automated analysis of exam questions according to Bloom's Taxonomy. Procedia - Social and Behavioral Sciences, v. 59, p. 297-303, 2012.

OTT, E.; PIRES, C. B. Estrutura curricular do curso de Ciências Contábeis no Brasil versus estruturas curriculares propostas por organismos internacionais: uma análise comparativa. Revista Universo Contábil, v. 6, n. 1, p. 28-45, 2010.

PELISSONI, A. M. S. Objetivos educacionais e avaliação da aprendizagem. Anuário da produção acadêmica docente, v. 3, n. 5, p. 129-139, 2010.

PINHEIRO, F. M. G.; DIAS FILHO, J. M.; LIMA FILHO, R. N.; LOPES, L. M. S. O perfil do contador e os níveis de habilidades cognitivas nos exames Enade e Suficiência do CFC: uma análise sob a perspectiva da Taxonomia de Bloom. Contextus Revista Contemporânea de Economia e Gestão, v. 11, n. 1, p. 50-65, 2013.

SANTANA JUNIOR, J. J. B.; PEREIRA, D. M. V. G.; LOPES, J. E. G. Análise das habilidades cognitivas requeridas dos candidatos ao cargo de contador na Administração Pública Federal, utilizando-se indicadores fundamentados na visão da Taxonomia de Bloom. Revista Contabilidade e Finanças, v. 19, n. 46, p. 108-121, 2008.

SILVA, S. C. Currículos dos cursos de Contabilidade: discussão em uma perspectiva educacional moderna e pós-moderna. Enfoque Reflexão Contábil, v. 34, n. 2, p. 15-36, 2015.

SLOMSKI, V. G.; GOMES, S. M. S.; SILVA, A. C. R.; GUIMARÃES, I. P. Mudanças curriculares e qualidade no ensino: ensino com pesquisa como proposta metodológica para a formação de contadores globalizados. Revista de Contabilidade e Organizações, v. 4, n. 8, p. 161-188, 2010.

SOUZA, P. V. S.; CRUZ, U. L.; LYRIO, E. F. A relação do Exame de Suficiência Contábil com o desempenho discente e a qualidade dos cursos superiores de Ciências Contábeis no Brasil. Revista Ambiente Contábil, v. 9, n. 2, p. 179-199, 2017. 